\title{
ON THE QUASI MONOTONE AND GENERALIZED POWER INCREASING SEQUENCES AND THEIR NEW APPLICATIONS
}

\author{
HÜSEYIN BOR
}

Abstract. In this paper, we prove a general theorem dealing with $|C, \alpha, \gamma, \beta ; \sigma|_{k}$ summability factors by using a general class of power increasing sequences instead of an almost increasing sequence. This theorem also includes several known and new results.

Mathematics subject classification (2010): 26D15, 40D15, 40F05, 40G05, $40 \mathrm{G} 99$.

Keywords and phrases: Quasi monotone sequences, power increasing sequences, Cesàro mean, summability factors, infinite series, Hölder inequality, Minkowski inequality.

\section{REFERENCES}

[1] N. K. BARI AND S. B. STEČKIN, Best approximation and differential properties of two conjugate functions, Trudy. Moskov. Mat. Obšč., 5 (1956), 483-522 (in Russian).

[2] R. P. BoAs, Quasi-positive sequences and trigonometric series, Proc. London Math. Soc. Ser. A, 14 (1965), 38-46.

[3] H. Bor, On a new application of quasi power increasing sequences, Proc. Est. Acad. Sci., 57 (2008), 205-209.

[4] H. Bor, On the generalized absolute Cesàro summability, Pac. J. Appl. Math., 2 (3) (2009), 35-40.

[5] H. Bor AND H. S. ÖZARsLan, A new application of quasi-monotone and almost increasing sequences, J. Comput. Anal. Appl., 13 (2011), 886-891.

[6] D. BorweIn, Theorems on some methods of summability, Quart. J. Math., Oxford Ser. (2), 9 (1958), 310-316.

[7] G. DAS, A Tauberian theorem for absolute summability, Proc. Camb. Phil. Soc., 67 (1970), 321-326.

[8] T. M. FLETT, On an extension of absolute summability and some theorems of Littlewood and Paley, Proc. London Math. Soc., 7 (1957), 113-141.

[9] T. M. FlETt, Some more theorems concerning the absolute summability of Fourier series, Proc. London Math. Soc., 8 (1958), 357-387.

[10] L. LeINDLER, A new application of quasi power increasing sequences, Publ. Math. Debrecen, 58 (2001), 791-796.

[11] W. T. Sulaiman, Extension on absolute summability factors of infinite series, J. Math. Anal. Appl., 322 (2006), 1224-1230.

[12] A. N. TunCER, On generalized absolute Cesàro summability factors, Ann. Polon. Math., 78 (2002), $25-29$. 